\title{
A bacterial esterase is homologous with non- haem haloperoxidases and displays brominating activity
}

\author{
Isabelle Pelletier and Josef Altenbuchner
}

Institut fü Industrielle Genetik der Universităt Stuttgart, Allmandring 31, D-70569 Stuttgart, Germany

\author{
Author for correspondence: Josef Altenbuchner. Tel: +497116856972. Fax: 497116856973. \\ e-mail : joe@gensun.biologie.uni-Stuttgart.de
}

\begin{abstract}
Screening GenBank indicated that an esterase from Pseudomonas fluorescens had high sequence similarity with bacterial non-haem haloperoxides. However, this homology was limited to two distinct domains of the published esterase sequence. As errors in the published sequence were suspected, the esterase gene was sequenced again. The revised sequence displayed between $\mathbf{4 0}$ and $\mathbf{5 0} \%$ identical amino acids with the haloperoxidases, but distributed along the whole sequence. In addition to the structural homologies with haloperoxidases, the esterase also displayed functional homology. The recombinant esterase, purified from Escherichia coli cells, was capable of both ester hydrolysis and halogenation, as detected in situ by the formation of bromophenol blue or spectrophotometrically by the bromination of monochlorodimedon. The esterase is thus a bifunctional enzyme. The sequence analysis and the biochemical investigations show that the esterase belongs to the haloperoxidase family. It also possessed, however, a typical feature of serine-hydrolases, namely the consensus motif Gly-X-Ser-X-Gly around the active serine of the catalytic triad. By alignment of the esterase with different serine-hydrolase sequences, it was possible to identify the other two residues of the triad. The triad comprised the residues Ser95, Asp223 and His252. Interestingly, a structurally equivalent catalytic triad was also identified in the sequences of all bacterial non-haem haloperoxidases, in highly conserved domains. The presence of a catalytic triad in haloperoxidases is expected to be important in the mechanism of halogenation.
\end{abstract}

Keywords: esterase, non-haem chloroperoxidase, Pseudomonas fuorescens, catalytic triad.

\section{INTRODUCTION}

Haloperoxidases are enzymes able to halogenate a wide variety of substrates in the presence of hydrogen peroxide and halide ions. The cloning and sequence analysis of four haloperoxidases from bacterial sources have pointed to a high degree of homogeneity. The four enzymes analysed are: bromoperoxidases BPO-A1 (Pelletier et al., 1994) and BPO-A2 (Pfeifer et al., 1992), both from Streptomyces aureofaciens ATCC 10762, a producer of 7-chlorotetracycline; chloroperoxidase CPO-P from Pseudomonas pyrro-

\footnotetext{
Abbreviations: $B P O$, bromoperoxidase; $C P O$, chloroperoxidase; $M C D$, monochlorodimedon; pNPA, 4-nitrophenylacetate; RBS, ribosomebinding site; RP, reverse primer; UP, universal primer.

The GenBank accession number for the sequence reported in this paper is U12537.
}

cinia, a producer of the chlorinated antifungal antibiotic pyrrolnitrin (Wolfframm et al., 1993); and chloroperoxidase CPO-L from Streptomyces lividans, which is not known to produce a halogenated compound (Bantleon et al., 1994). They displayed high similarity to each other with regard to both structural and catalytic features.

These four enzymes differ considerably from previously characterized haloperoxidases such as (i) various wellinvestigated haem-type haloperoxidases (Dawson \& Sono, 1987), for example the BPO from the green alga Penicillus capitatus (Manthey \& Hager, 1989), and (ii) the metal-containing haloperoxidases, for example the vanadium-containing BPO from the brown alga Ascophyllum nodosum (De Boer \& Wever, 1988), in that they do not contain a prosthetic group or a metal ion to perform the halogenation reaction. Therefore, the bacterial non-haem haloperoxidases form a totally distinct 
enzyme family, probably with unique features involved in their catalytic mechanism.

Recently, a major contribution to the understanding of the structure-function relationships among these haloperoxidases has resulted from screening databases for sequences similar to haloperoxidases. This revealed that a protein described as an aryl-esterase from Pseudomonas fuorescens (accession number gp/D12484/; Choi et al., 1990) displays surprisingly high homology with CPO-L from S. lividans (32\% identical amino acids). However, careful comparison of the esterase and chloroperoxidase sequences led us to suppose that there were mistakes in the published esterase gene sequence. When three regions of the esterase gene were translated in the two other frames, the overall homology between the deduced protein and CPO-L increased from 32 to $50 \%$. In order to clarify this intriguing result and to further investigate the relationship between the esterase of $P$. fuorescens and the bacterial haloperoxidases, a plasmid bearing the esterase gene was obtained from O. J. Yoo (Taejon, Korea).

In this study, we report the new sequence analysis of the esterase gene and of the deduced protein, allowing sequence comparisons with the bacterial haloperoxidases. Production of the esterase from Escherichia coli cells enabled us to perform comparative studies with the four bacterial haloperoxidases referred to above. Furthermore, purification of the esterase and of CPO-P allowed us to carry out biochemical investigations and to compare more precisely the catalytic features of the two enzymes.

\section{METHODS}

Materials. Monochlorodimedon (MCD), phenol red, hydrogen peroxide $(30 \%, v / v) 4$-nitrophenyl acetate ( $p$ NPA), 2-naphthyl acetate, phenyl acetate, Diazo Blue B (tetraazotized 0 dianisidine) and tributyrin were purchased from Sigma. X-Gal, IPTG, ampicillin, restriction endonucleases, calf intestinal alkaline phosphatase (CIAP) and bacteriophage T4 DNA ligase were obtained from Boehringer Mannheim. Low melting point Seaplaque GTG agarose was from Biozym Diagnostic. Bio-Rad Protein Assay was from Bio-Rad.

Strains, plasmids and growth conditions. E. coli JM109 (Yanisch-Perron, 1985) was used as host for expression of the chloroperoxidase and esterase genes from Pseudomonas strains. A $1.5 \mathrm{~kb}$ EcoRI DNA fragment bearing the $c p o P$ gene from Pseudomonas pyrrocinia on the plasmid pHM321 (Wolframm et al., 1993) was inserted into the EcoRI site of the high-copynumber plasmid pBTac1 (Brosius et al., 1981), with cpoP expression under the control of the inducible tac promoter, resulting in pIP50. The esterase gene from Pseudomonas fuorescens SIK WI (Choi et al., 1990) was kindly provided by O. J. Yoo (Department of Life Science, Taejon, Korea), on the plasmid pUE1251, which consisted of a $1 \cdot 2 \mathrm{~kb}$ Pst I DNA fragment inserted into the PstI site of pUC19 (Yanisch-Perron, 1985), with the esterase expression under the control of the lac promoter. pIP50 and pUE1251 were used to transform JM109 cells and transformants were selected on agar plates containing $100 \mu \mathrm{g}$ ampicillin $\mathrm{ml}^{-1}, 40 \mu \mathrm{g} \mathrm{X}-\mathrm{Gal} \mathrm{ml} \mathrm{l}^{-1}$ and $0.2 \mathrm{mM}$ IPTG. E. coli JM109 cells containing PIP50 or pUE1251 were grown at $37^{\circ} \mathrm{C}$ in Luria-Bertoni broth supplemented with ampicillin until the early exponential phase $\left(\mathrm{OD}_{600} 0 \cdot 5\right)$. Gene expression was then induced by adding $0.1 \mathrm{mM}$ IPTG to the cultures, followed by further incubation for $3 \mathrm{~h}$ at $30^{\circ} \mathrm{C}$.
Preparation and analysis of protein samples. Crude cell extracts were prepared by resuspending E. coli cells in $100 \mathrm{mM}$ sodium acetate $\mathrm{pH} 5.5$ to carry out bromoperoxidase assays, or in $10 \mathrm{mM}$ potassium phosphate buffer $\mathrm{pH} 7$ to perform esterase assays. Cells were disrupted by sonication with a sonifier (Sonicator W-385, Ultrasonics microtip, $6 \times 30 \mathrm{~s}$ pulse $50 \% \mathrm{~s}^{-1}$ at $4{ }^{\circ} \mathrm{C}$ ) and cell debris removed by centrifugation to give a clear lysate. Protein concentrations were determined at $595 \mathrm{~nm}$ using the method of Bradford (1976) with bovine serum albumin as standard. Enzyme expression was monitored by loading crude extracts on a $12 \%(\mathrm{w} / \mathrm{v})$ SDS-PAGE gel using the discontinuous buffer system of Laemmli (1970). Gels were stained for proteins with Serva Blue R (Serva Feinbiochemica). Proteins from the low $-M_{\mathrm{r}}$ calibration kit from Pharmacia were used as standard. The $M_{\mathrm{r}}$ of the esterase was estimated from a plot of $\log M_{\mathrm{r}}$ versus mobility using the standard proteins.

Analytical isoelectric focusing was performed with a PhastGel IEF as recommended by Pharmacia, containing ampholytes in the $\mathrm{pH}$ range 3-9. The $\mathrm{pI}$ of the esterase was calculated from a plot of $\mathrm{pI}$ versus mobility using standard proteins in the $\mathrm{pI}$ range 4.6-9.6 (IEF Standards, Bio-Rad).

Enzyme assays. Esterase production by cells containing pUE1251 or pIP50 was directly tested in an agar diffusion plate assay: agar plates were overlaid by a soft agar containing an emulsion of $1 \%(\mathrm{v} / \mathrm{v})$ tributyrin (Kugimiya et al., 1986). Lipolytic activity was indicated by a halo of hydrolysis around the colonies.

Brominating and esterase activities were assayed in situ on native $10 \%(\mathrm{w} / \mathrm{v})$ PAGE gels. Brominating activity was detected by the conversion of the substrate phenol red to bromophenol blue (Loo et al., 1964). Esterase activity was detected in situ using the procedure described by Rosenberg et al. (1975), with phenyl acetate or 2-naphthyl acetate as substrates and Diazo Blue B as coupling agent.

Brominating activity was also determined spectrophotometrically with the substrate $\operatorname{MCD}\left(\varepsilon=19 \cdot 910^{3} \mathrm{M}^{-1} \mathrm{~cm}^{-1}\right)$ at $290 \mathrm{~nm}$ (Hewson \& Hager, 1980; Pfeifer et al., 1992). One unit bromoperoxidase activity was defined as the amount of enzyme catalysing the formation of $1 \mu \mathrm{mol}$ monobromomonochlorodimedon $\min ^{-1}$ at $25^{\circ} \mathrm{C}$. Esterase activity was measured in a colorimetric assay in $10 \mathrm{mM}$ potassium phosphate buffer pH 7 using pNPA (1 mM dissolved in DMSO) as substrate (Donnelly \& Crawford, 1988). The amount of 4-nitrophenol released by the esterase activity was determined at $410 \mathrm{~nm}(\varepsilon=$ $\left.16.510^{3} \mathrm{M}^{-1} \mathrm{~cm}^{-1}\right)$. One unit of activity was defined as the amount of enzyme releasing $1 \mu \mathrm{mol} 4$-nitrophenol $\mathrm{min}^{-1}$ at $\mathrm{pH} 7$ and $25^{\circ} \mathrm{C}$. Determination of the $\mathrm{pH}$ optimum was carried out in $10 \mathrm{mM}$ potassium phosphate buffer in the $\mathrm{pH}$ range 4-9.

Purification of the esterase and CPO-P from E. coli. Crude cell extract from a $500 \mathrm{ml}$ culture ( $5 \mathrm{~g}$ wet weight cells) was diluted $1: 20$ in water and fractionated by anion-exchange chromatography (Mono Q, Pharmacia). The column was equilibrated with $10 \mathrm{mM}$ potassium phosphate $\mathrm{pH}$ 7. Proteins were eluted with a linear gradient of 0 to $1 \mathrm{M}$ sodium chloride in $10 \mathrm{mM}$ potassium phosphate buffer $\mathrm{pH}$. Fractions of $1 \mathrm{ml}$ were collected and assayed for protein $\left(A_{280}\right)$ and esterase $\left(A_{410}\right)$ activity. Fractions containing at least $50 \%$ of the esterase activity of the most active fraction were pooled and concentrated in an ultrafiltration cell (YM-10 membrane, Amicon). A similar protocol was used to purify CPO-P from crude extracts of cells containing PIP50. Fractions of $1 \mathrm{ml}$ collected from the Mono $\mathrm{Q}$ column were assayed for protein $\left(A_{280}\right)$ and bromoperoxidase $\left(A_{290}\right)$ activity. Fractions containing CPO-P were combined and concentrated by ultrafiltration.

DNA manipulation. Plasmid DNA was isolated from E. coli 
strains using an alkaline lysis procedure followed by spermine precipitation (Kieser, 1984). DNA digestion with restriction enzymes, dephosphorylation with alkaline phosphatase, filling in of cohesive ends with the large fragment of DNA polymerase I (Klenow fragment), and ligation with T4 DNA ligase were performed according to Sambrook et al. (1989). DNA restriction fragments were purified by elution from low-melting-point agarose gels as described by Parker \& Seed (1980). Transformation of E. coli JM109 was carried out according to Chung et al. (1989).

Nucleotide sequence analysis. This was carried out in an automated DNA sequencing system (ALF-sequencer; Pharmacia) as described previously (Pelletier et al., 1994), using the fluorescent-labelled universal primer (UP) and reverse primer (RP) and the AutoRead Sequencing Kit from Pharmacia. Double-stranded DNA of pUC19-derivative plasmids used as the template for DNA sequencing was prepared with the Quiagen DNA preparation kit (QIAwell-8 Plasmid Kit). Strong compressions in sequencing gels due to stable secondary structures were resolved by the use of 7-deaza dATP in addition to 7-deaza dGTP provided by the kit. The computer analysis of sequence data was performed on a Microvax work station 3200, using the Sequence Analysis Software Program version 7.3 of the University of Wisconsin, Genetics Computer Group (Devereux et al., 1984). The statistical analysis of codon utilization was performed with the CODON PREFERENCE program (Gribskov et al., 1984), using a codon usage table of Pseudomonas generated from the analysis of 259 Pseudomonas genes (Wada et al., 1992). Database searches were run with the programs BLASTN, BLASTP and TBLASTN (Altschul et al., 1990) on the BLAST electronic-mail server from the National Center for Biotechnology Information, Bethesda, MD, USA. Protein alignments were performed with the programs BESTFIT, LINEUP and PILEUP.

\section{RESULTS}

\section{Subcloning and nucleotide sequence analysis of the esterase gene}

The nucleotide sequence of the $1.2 \mathrm{~kb}$ Pst I fragment on pUE1251 has been newly determined, using a double- stranded DNA sequencing protocol. The sequencing strategy is shown in Fig. 1 which indicates the deletions generated at either end of the insert to get the overall DNA sequence on both strands, using the fluorescent UP and RP primers. Fig. 2 shows the nucleotide sequence of the esterase gene, corrected at 15 positions in comparison with the one published previously (Choi et al., 1990). Computer analysis of the sequence on both strands allowed the identification of one large ORF, matching perfectly the codon usage of Pseudomonas genes (not shown). This 816 bp ORF extends from the start codon ATG at position 248 to the stop codon TGA at position 1064 and encodes a predicted protein of 272 amino acids. The average $\mathrm{G}+\mathrm{C}$ content $(62 \mathrm{~mol} \%)$ of the esterase encoding sequence is typical for Pseudomonas genes.

In contrast, the codon preference analysis of the published esterase gene showed a low accordance with the Pseudomonas codon usage, with the presence of a large number of 'rare codons' in the central part of the gene and at its $3^{\prime}$ end. It was caused by five frameshifts in the coding sequence of the esterase, generated in regions particularly difficult to sequence.

The $5^{\prime}$ end of the esterase gene is in agreement with the one previously described. Furthermore, the $\mathrm{N}$-terminal part of the predicted protein sequence is identical with the one determined by Edman degradation of the purified esterase, which gave the sequence S-T-F-V-A-K-D-G-TQ-I-Y-F-K-D-W-G (Choi et al., 1990). However, the revised ORF encodes a putative protein of 272 amino acids, with a calculated $M_{\mathrm{r}}$ of 30092 , instead of a 236 amino acid protein with a calculated $M_{\mathrm{r}}$ of 26936 as previously published. The new $M_{\mathrm{r}}$ of the deduced protein was more in agreement with the $M_{\mathrm{r}}$ of the esterase estimated by SDS-PAGE $(29 \cdot 5 \mathrm{kDa})$.

The esterase gene (Fig. 2) is preceded by a putative Shine-Dalgarno motif, AGGAG, 7 bp upstream of the start codon, and potential E. coli-type promoter sequences

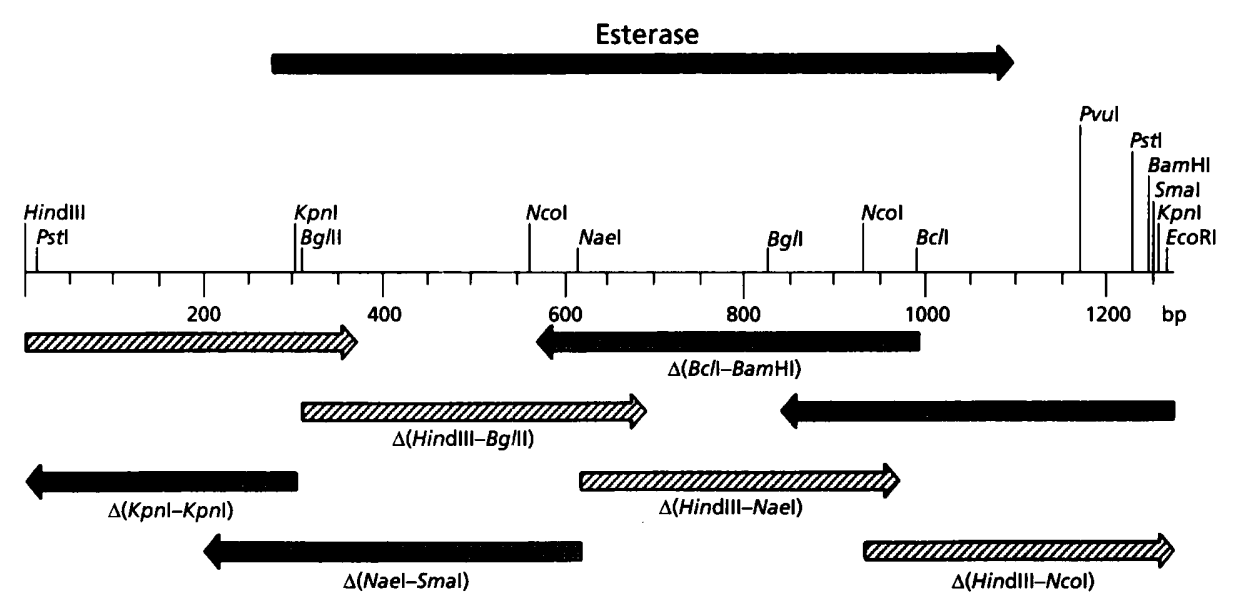

Fig. 1. Sequencing strategy of the $1.2 \mathrm{~kb}$ Pstl DNA fragment on pUE1251. Different deletions of the $1.2 \mathrm{~kb}$ insert were generated using a restriction site in the polycloning site and a second within the insert, as indicated below each arrow. The arrows indicate the nucleotide sequence obtained for each subclone, using the UP (filled leftwards arrows) and RP (diagonally hatched rightwards arrows). 
1 (Sau3A)AatII

GATCTGGACGTCCTCGGCCCCCGGCGCGCGGCGTCGAAGGTGAAGGGCTTGAGGGCATCCTTGGCGTTCTGGGCGGCGTAGCTGTAAGTC CTAGACCTGCAGGAGCCGGGGGCCGCGCGCCGCAGCTTCCACTTCCCGAACTCCCGTAGGAACCGCAAGACCCGCCGCATCGACATTCAG

$91-35$

TTGGCCATTTCGTTCACCTGTGTGATCTGACGGTAGAGGTCAGTGGACCAGCATAGACGCTGAACCGTTCAACCGAGCACACCGGTACAA AACCGGTAAAGCAAGTGGACACACTAGACTGCCATCTCCAGTCACCTGGTCGTATCTGCGACTTGGCAAGTTGGCTCGTGTGGCCATGTT

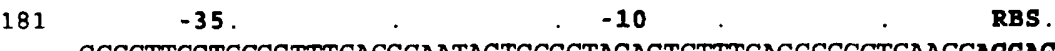

GCCCTTCGTCCGGTTTCACGCAATAGTGCGCTAGAGTCTTTCAGCCCCCTCAACCAGGAGTTTTTGCATGAGCACATTTGTTGCAAAAGA CGGGAAGCAGGCCAAAGTGCGTTATCACGCGATCTCAGAAAGTCGGGGGAGTTGGTCCTCAAAAACGTACTCGTGTAAACAACGTTTTCT

271 KpnI BgIII

CGGTACCCAGATCTATTTCAAGGACTGGGGCAGCGGTAAACCGGTGTTGTTCAGCCACGGTTGGCTACTGGATGCCGACATGTGGGATA GCCATGGGTCTAGATAAAGTTCCTGACCCCGTCGCCATTTGGCCACAACAAGTCGGTGCCAACCGATGACCTACGGCTGTACACCCTTAT

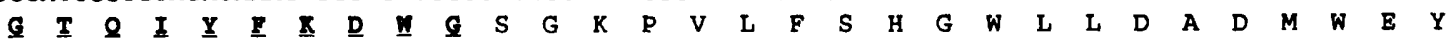

CCAGATGGAGTACCTCAGCAGCCGCGGCTATCGCACCATCGCCTTTGACCGCCGCGGCTTTGGCCGCTCGGACCAACCCTGGACCGGCAA GGTCTACCTCATGGAGTCGTCGGCGCCGATAGCGTGGTAGCGGAAACTGGCGGCGCCGAAACCGGCGAGCCTGGTTGGGACCTGGCCGTT

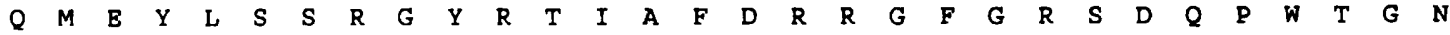

CGACTACGACACCTTCGCCGACGACATCGCCCAGTTGATCGAACACCTGGACCTCAAGGAGGTGACCCTGGTGGGCTTCTCCATGGGCGG GCTGATGCTGTGGAAGCGGCTGCTGTAGCGGGTCAACTAGCTTGTGGACCTGGAGTTCCTCCACTGGGACCACCCGAAGAGGTACCCGCC $\begin{array}{lllllllllllllllllllllllllllllll}D & Y & D & T & F & A & D & D & I & A & Q & \text { L } & \text { I } & \text { E } & \text { H } & \text { L } & \text { D } & \text { L } & \text { K } & \text { E } & \text { V } & \text { T } & \text { L } & \text { V } & \mathbf{G} & \boldsymbol{F} & \mathbf{S} & M & \mathbf{G} & G\end{array}$

CGGCGATGTGGCCCGCTACATCGCCCGCCACGGCAGCGCACGGGTGGCCGGCCTGGTGCTGCTGGGCGCCGTCACCCCGCTGTTCGGCCA GCCGCTACACCGGGCGATGTAGCGGGCGGTGCCGTCGCGTGCCCACCGGCCGGACCACGACGACCCGCGGCAGTGGGGCGACAAGCCGGT $\begin{array}{llllllllllllllllllllllllllllllll}G & D & V & A & R & Y & I & A & R & H & G & S & A & R & V & A & G & \text { L } & \text { V } & \text { L } & \text { L } & G & \text { A } & \text { V } & \text { T } & \text { P } & \text { L } & F & G & Q\end{array}$

GAAGCCCGACTATCCGCAGGGTGTCCCGCTCGATGTGTTCGCAAGGTTCAAGACTGAGCTGCTGAAGGATCGCGCGCAGTTCATCAGCGA CTTCGGGCTGATAGGCGTCCCACAGGGCGAGCTACACAAGCGTTCCAAGTTCTGACTCGACGACTTCCTAGCGCGCGTCAAGTAGTCGCT

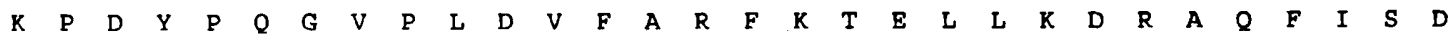

TTTCAACGCACCGTTCTATGGCATCAACAAGGGCCAGGTCGTCTCCCAAGGCGTGCAGACCCAGACCCTGCAAATCGCCCTGCTGGCCTC AAAGTTGCGTGGCAAGATACCGTAGTTGTTCCCGGTCCAGCAGAGGGTTCCGCACGTCTGGGTCTGGGACGTTTAGCGGGACGACCGGAG

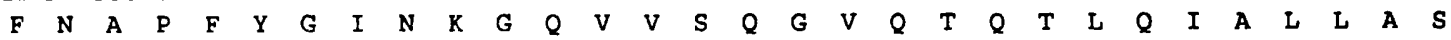

GCTCAAGGCCACGGTGGATTGCGTCACCGCGTTCGCCGAAACCGACTTCCGCCCGGACATGGCCAAGATCGACGTACCCACCCTGGTGAT CGAGTTCCGGTGCCACCTAACGCAGTGGCGCAAGCGGCTTTGGCTGAAGGCGGGCCTGTACCGGTTCTAGCTGCATGGGTGGGACCACTA

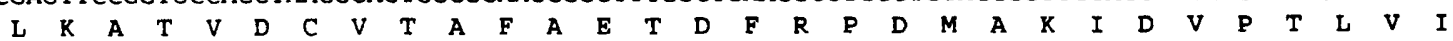

CCATGGCGATGGCGACCAGATCGTGCCGTTCGAGACCACCGGCAAAGTGGCGGCGGAGTTGATCAAGGGCGCCGAACTGAAGGTGTACAA GGTACCGCTACCGCTGGTCTAGCACGGCAAGCTCTGGTGGCCGTTTCACCGCCGCCTCAACTAGTTCCCGCGGCTTGACTTCCACATGTT $\begin{array}{llllllllllllllllllllllllllllll}\text { H } & G & \text { D } & G & \text { D } & Q & \text { I } & \text { V } & \text { P } & \text { F } & \text { E } & \text { T } & \text { T } & \text { G } & \text { K } & \text { V } & \text { A } & \text { A } & \text { E } & \text { L } & \text { I } & \text { K } & \text { G } & \text { A } & \text { E } & \text { L } & \text { K } & \text { V } & \text { Y } & \text { K }\end{array}$

GGACGCGCCCCACGGGTTCGCGGTGACCCACGCCCAGCAGTTGAACGAAGACCTGTTGGCGTTCTTGAAACGCTGAGTTAATGTCTGCCT CCTGCGCGGGGTGCCCAAGCGCCACTGGGTGCGGGTCGTCAACTTGCTTCTGGACAACCGCAAGAACTTTGCGACTCAATTACAGACGGA $\begin{array}{lllllllllllllllllllllllll}\text { D } & \text { A } & \text { P } & \text { H } & \text { G } & \text { F } & \text { A } & \text { V } & \text { T } & \text { H } & \text { A } & \mathbf{Q} & \mathbf{Q} & \text { L } & \text { N } & \text { E } & \text { D } & \text { L } & \text { L } & \text { A } & \text { F } & \text { L } & K & R & \text { * }\end{array}$ AATAGCCGGCCCGAACGGGCCGGAAAAAAAATGCGCGAGCTTAGAGCGCGCCAGCGGCCCGTGCTAGCACGACTTGGCGGCGGGGGAGCG

Fig. 2. For legend see facing page. 


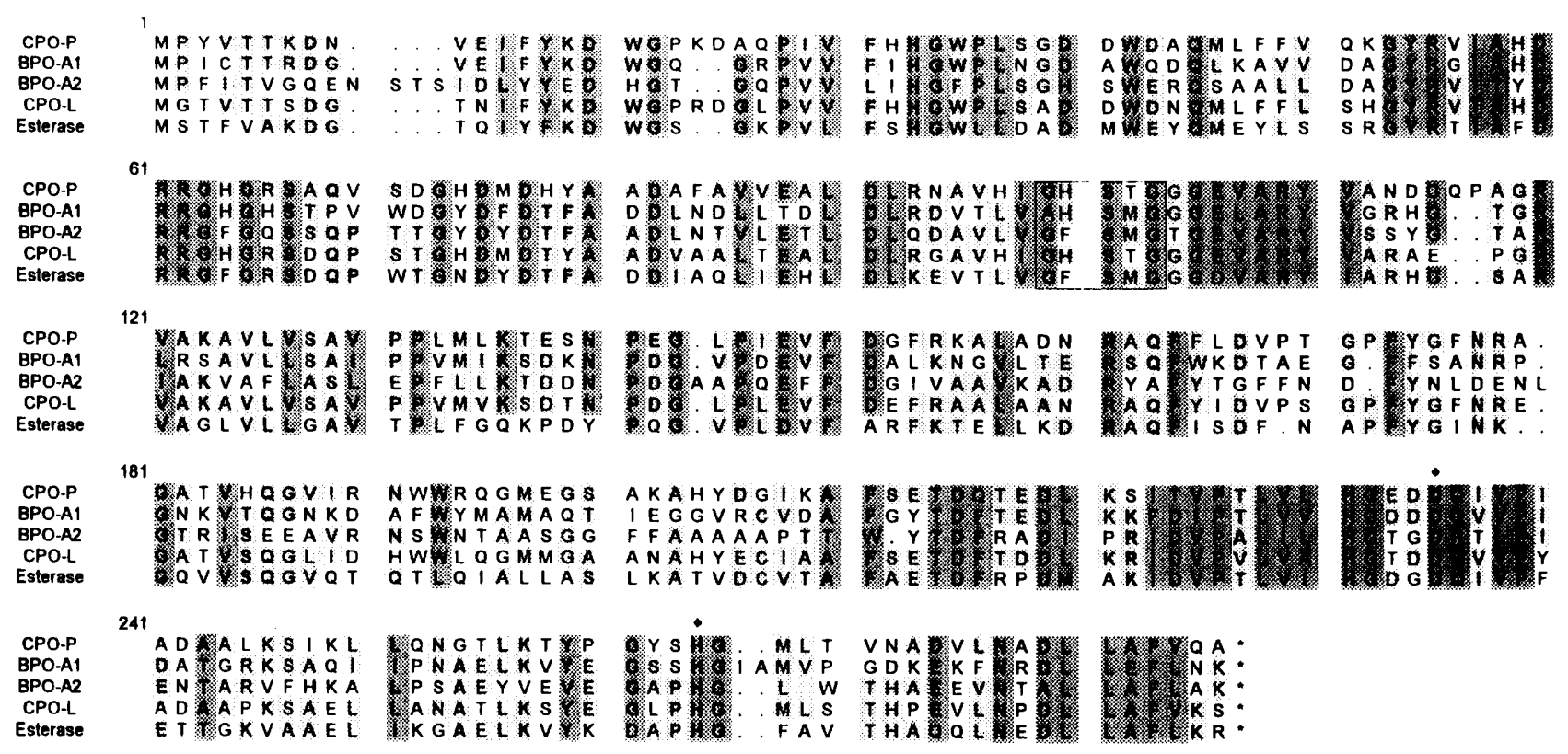

Fig. 3. Alignments of the esterase of $P$. fluorescens with the bacterial non-haem haloperoxidases BPO-A1 (Pelletier et al., 1994) and BPO-A2 (Pfeifer et al., 1992) (bromoperoxidases from S. aureofaciens), CPO-P (a chloroperoxidase from P. pyrrocinia, Wolfframm et al., 1993) and CPO-L (a chloroperoxidase from S. lividans, Bantleon et al., 1994). Identical residues are indicated by a dark grey background and conservative substitutions by a pale grey background. The amino acids considered as similar are: $(D, E),(N, Q),(R, K),(A, S, T),(I, L, M, V)$ and $(F, Y, W)$. The end of each protein is indicated by an asterisk. The catalytic serine-motif around position 101 is boxed. The aspartate and histidine residues which are thought to be involved in the catalytic triad are marked with a diamond.

$(-35$ and -10$)$ have also been found in the $5^{\prime}$-flanking region. Furthermore, a perfect inverted repeat is present $19 \mathrm{bp}$ downstream of the TGA termination codon, between positions 1086 and 1103 , giving a potential stem-loop structure with a calculated $\Delta G$ of $-23 \mathrm{kcal} \mathrm{mol}^{-1}\left(-96 \mathrm{~kJ} \mathrm{~mol}^{-1}\right)$. The presence of a poly(T) stretch immediately downstream of the palindromic sequence suggests that this structure is a rhoindependent transcription terminator of the esterase gene (Rosenberg \& Court, 1979).

\section{Homology between the esterase and bacterial non- haem haloperoxidases}

Using the BESTFIT and LINEUP programs, the deduced amino acid sequence of the esterase was compared with four bacterial non-haem haloperoxidases with known sequences: BPO-A1 (Pelletier et al., 1994) and BPO-A2
(Pfeifer et al., 1992), the two bromoperoxidases from $S$. aureofaciens ATCC 10762; CPO-P, the chloroperoxidase from P. pyrrocinia (Wolfframm et al., 1993); and CPO-L, the chloroperoxidase from S. lividans (Bantleon et al., 1994). The esterase and haloperoxidases displayed a high degree of similarity in length, from 272 amino acid residues for the esterase to 278 residues for BPO-A2. The overall primary structures of the five proteins were highly related, permitting a multi-alignment (Fig. 3) with only a few gaps to generate an optimal matching of all sequences. Highly conserved domains were found in the N-terminal half of the five proteins, extending over the first 150 amino acids. In the second half, two shorter conserved regions were identified, located between residues 210 and 240 , and from position 255 to the C-terminal end. The similarity score of the five proteins along their overall primary structures is plotted in Fig. 4(a). It indicates a more variable domain in the central part of the halo-

Fig. 2. Revised nucleotide sequence of the esterase gene from $P$. fluorescens and its flanking regions, differing at 15 positions compared with the sequence data published by Choi et al. (1990). The Pstl and Sau3A sites used for the cloning of the esterase gene after partial digestion are indicated. The restriction sites used to generate deletions in the esteraseencoding fragment are shown. Numbering on the left side refers to the nucleotide sequence and numbering on the right to the deduced amino acid sequence displayed below with the one-letter code. The $\mathrm{N}$-terminal portion of the esterase previously determined by Edman degradation is indicated in bold letters and underlined. The conserved region surrounding the active-site serine residue Ser95 is double-underlined. The potential -10 and -35 promoter sequences and ribosome-binding site identified in the $5^{\prime}$ non-coding region of the esterase gene are indicated. A 9 bp sequence directly repeated upstream and downstream of the esterase gene is labelled ${ }^{\circ}$ ). The palindrome sequence followed by a poly $(T)$ stretch in the $3^{\prime}$ flanking region is presumably the transcriptional terminator of the gene. 


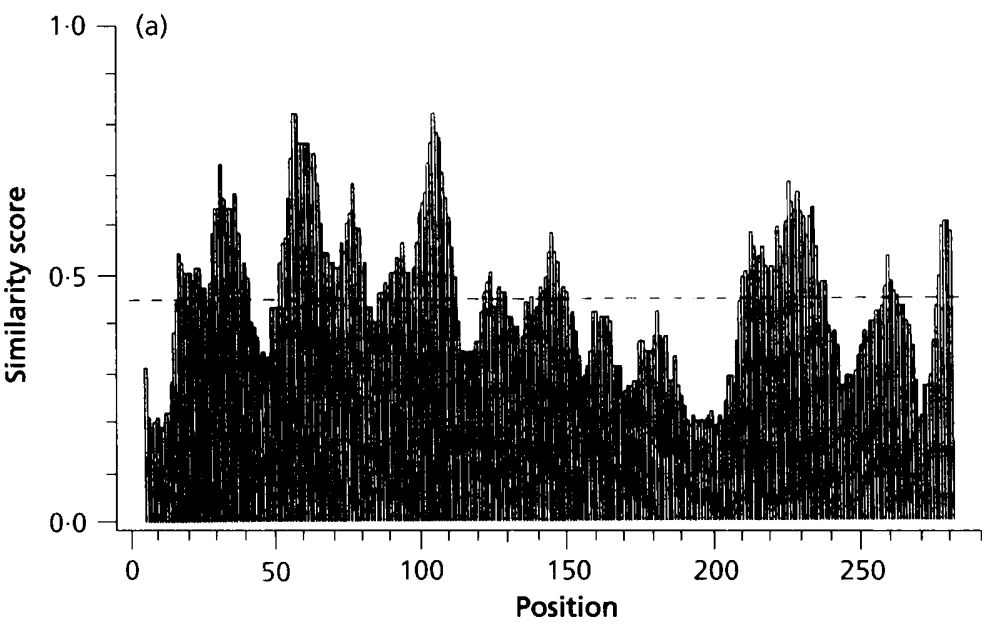

(b)

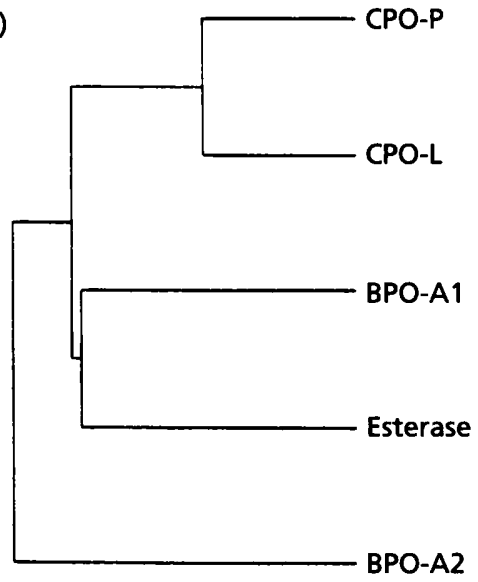

Fig. 4. Similarity plot and phylogenetic tree of the esterase and the bacterial haloperoxidases. (a) The similarity score between the protein sequences previously aligned with the PILEUP program is calculated along the overall alignment between the amino acid positions 1 and 285 (numbering refers to Fig. 3). The plot above the dashed line indicates the presence of highly conserved domains in the five proteins. (b) Phylogenetic tree of the bacterial non-haem haloperoxidases and the esterase of $P$. fluorescens.

peroxidases and the esterase between positions 150 and 210. Considering the putative heterogeneity of substrate specificity among the bacterial haloperoxidases (Weng et al., 1991; Wolfframm et al., 1993), this variable domain should be involved in substrate recognition.

To determine the evolutionary distance between the esterase and haloperoxidases, a phylogenetic tree was constructed by using the PILEUP program. As shown in Fig. 4(b), the four haloperoxidases from bacterial sources are closely related to each other, forming an homogenous enzyme family. The esterase of $P$. fluorescens fits perfectly into the haloperoxidase family, sharing the greatest number of identical amino acids with CPO-L and BPOA1 (50\% and $46 \%$ identical amino acids, respectively). However, the highest overall score of similarity was calculated for BPO-A1 $(68.8 \%)$. Furthermore, we observed that the esterase is even more closely related to the haloperoxidase group containing BPO-A1, CPO-L and CPO-P than is BPO-A2.

\section{Purification of the esterase of $\boldsymbol{P}$. fluorescens produced in E. coli JM109(pUE1251)}

Protein samples prepared from E. coli JM109(pUE1251) grown under inducing conditions were analysed by SDSPAGE. A protein with an $M_{\mathrm{r}}$ of 29500 was produced in large amounts by JM109 cells bearing pUE1251 but was absent in extracts from JM109 carrying the plasmid without insert. The clone carrying pUE1251 was tested for its ability to display esterase activity on agar plates overlaid with an emulsion of $1 \%$ tributyrin. Esterase activity could be detected by the formation of a halo of hydrolysis, in contrast with the clones carrying pIP50 (encoding CPO-P) or pUC19, which did not produce haloes on this medium (data not shown).
In preliminary experiments, crude extracts of $E$. coli JM109(pUE1251) were loaded onto native PAGE gels and stained either for esterase activity with $p$ NPA or for brominating activity with phenol red. We observed that the esterase of $P$. fluorescens exhibits both types of activity. However, attempts to detect the brominating activity of the esterase in the spectrophotometric assays with MCD as substrate were unsuccessful. This apparent discrepancy has been previously reported in crude extracts of E. coli (Wolfframm et al., 1993) and S. lividans (Weng et al., 1991). It is assumed that in crude extracts an inhibitor of bromination is present or a competitive reaction occurs, leading to the depletion of one of the substrates required for bromination. Fractionation of crude extracts on native PAGE avoids this inhibitory effect but purification of crude extract is required prior to performing spectrophotometric measurements.

Crude extract of E. coli JM109(pUE1251) (50 mg protein) was fractionated by anion-exchange chromatography. The elution profile displayed a sharp peak of esterase activity eluted with about $0.5 \mathrm{M}$ sodium chloride. This purification step resulted in a 7.4-fold enrichment of the esterase, with a $70 \%$ recovery. The specific esterase activity in the standard assay with $p$ NPA as substrate was $89 \mathrm{U}$ (mg protein $)^{-1}$. No comparison can be made with published results which have been obtained with the substrate methyl acetyl salicylate (Choi et al., 1990). The partially purified esterase gave a highly dominant band with an apparent $M_{\mathrm{r}}$ of 29500 as measured by SDSPAGE.

The $\mathrm{pI}$ of the esterase was determined by isoelectric focusing of the purified esterase in the native form. The esterase stained with Coomassie blue for protein and with $p$ NPA for esterase activity migrated with a $\mathrm{pI}$ of $4 \cdot 4$, as determined by simultaneous migration of calibration 
proteins. This value is in good agreement with the calculated isoelectric point of the esterase subunit ( $\mathrm{pI}=$ 5.4 ), in contrast with the pI of 11.9 deduced from the previously published esterase sequence. The pl of 4.4 is also compatible with experimental observations: the esterase was purified by anion-exchange chromatography

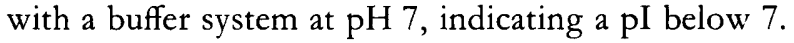

To carry out comparative studies of the esterase and CPO$\mathrm{P}$, it was necessary to purify CPO-P from crude extract of E. coli. Fractionation of crude extract by anion-exchange chromatography was performed using the same procedure as that used for the esterase. The brominating activity of CPO-P was enriched $7 \cdot 5$-fold, with a $74 \%$ recovery. The specific brominating activity of CPO-P was $47 \mathrm{U}$ (mg protein $)^{-1}$. The published value (Wolfframm et al., 1993) for the purified enzyme is $63 \mathrm{U}$ (mg protein) ${ }^{-1}$, indicating that we obtained CPO-P with a degree of purification of $75 \%$.

\section{In situ detection of brominating and esterase activities}

Fractions enriched in the esterase and CPO-P obtained by anion-exchange chromatography were loaded onto native PAGE gels and stained either for brominating activity or for esterase activity (data not shown). Whereas, in situ CPO-P exhibited only brominating activity, the esterase of $P$. fluorescens showed both activities. However, $20 \mu \mathrm{g}$ protein was required to detect the brominating activity in the case of the esterase, whereas only $0.05 \mu \mathrm{g}$ protein was necessary for CPO-P. These results indicated firstly, that the esterase is a bifunctional enzyme, and secondly, that the esterase is not only structurally, but also functionally related to haloperoxidases. Furthermore, the haloperoxidases BPO-A1, BPO-A2 and CPO-L, tested in the same way by native PAGE, showed the same behaviour as CPO-P: they exhibited only brominating activity. Esterase activity could not be detected in situ when phenyl acetate, 2-naphthyl acetate or tributyrin were used as substrates (data not shown).

\section{Catalytic features of the esterase and of CPO-P}

The esterase activity of the purified esterase was measured spectrophotometrically using $\mathrm{pNPA}$ as substrate. The $\mathrm{pH}$ optimum for esterase activity in potassium phosphate buffer was above 9. Maximum esterase activity was observed at $70^{\circ} \mathrm{C}$. An apparent $K_{\mathrm{m}}$ for pNPA of $92 \mu \mathrm{M}$ was estimated from Lineweaver-Burk plots. The purified fraction of CPO-P was also assayed for esterase activity by the colorimetric assay with $p$ NPA. Whereas CPO-P did not exhibit any detectable esterase activity at $\mathrm{pH} 5 \cdot 5$, hydrolysis of $p$ NPA could be measured at higher $\mathrm{pH}$. A maximum specific esterase activity of $1.8 \mathrm{U}(\mathrm{mg} \text { protein })^{-1}$ was obtained at $\mathrm{pH} 8.5$ for CPO-P.

The brominating activity of the esterase was also studied spectrophotometrically. The specific brominating activity of the esterase was $0 \cdot 1 \mathrm{U}(\mathrm{mg} \text { protein })^{-1}$, using the MCD assay. For comparison, the specific brominating activity of purified CPO-P was $47 \mathrm{U}$ (mg protein) ${ }^{-1}$. The two brominating activities could be differentiated by their $\mathrm{pH}$ and temperature optima. Maximum brominating activity in $1 \mathrm{M}$ sodium acetate was observed at $\mathrm{pH} 6$ and $55^{\circ} \mathrm{C}$ for $\mathrm{CPO}-\mathrm{P}$, but at $\mathrm{pH} 5$ and $50^{\circ} \mathrm{C}$ for the esterase.

\section{DISCUSSION}

Screening GenBank with the TBLASTN program indicated that an esterase from $P$ seudomonas fluorescens had significant homology with the bacterial haloperoxidases. However, this homology was only found in two distinct domains of the published esterase sequence. As errors in the published sequence were suspected, the esterase gene was sequenced again (Figs 1 and 2).

The deduced amino acid sequence differs from the one published due to the correction of five frameshifts. When scanned with the CODON PREFERENCE program, the corrected ORF encoding the esterase is now in very good agreement with the codon usage of Pseudomonas genes. The predicted esterase sequence displays a very high score of identical amino acids with all haloperoxidases along their overall sequences (Fig. 3), between $40 \%$ with BPOA 2 and $50 \%$ with CPO-L. However, the similarity plot (Fig. 4a) displays more strongly conserved domains in the $\mathrm{N}$-terminal and at the C-terminal ends of the five proteins.

The relationship of the esterase to the bacterial haloperoxidase family can be visualized by a phylogenetic tree (Fig. 4b). This points to a probable common ancestor for the esterase, BPO-A1, CPO-L and CPO-P, whereas an earlier divergence could have occurred for the BPO-A2 ancestor. Immunological studies of the esterase have been carried out to check for a putative cross-reaction between the esterase and haloperoxidases. The esterase was detected on Western blots using antibodies raised against CPO-P (kindly provided by K.-H. van Pée), confirming their structural relationship (unpublished results).

Biochemical investigations were performed to determine whether the structural homology between the esterase and haloperoxidases also reflected functional homology. Preliminary experiments revealed that the esterase, expressed in E. coli cells containing pUE1251, displayed in addition to the expected esterase activity, the characteristic staining pattern for brominating activity in the phenol red assay used routinely for haloperoxidases. However, attempts to measure brominating activity in the spectrophotometric assay with MCD as substrate were only successful after fractionation of crude extracts of E. coli containing pUE1251 by anion-exchange chromatography. In the purification protocol reported by Choi et al. (1990), the esterase was isolated from the periplasmic fraction of $E$. coli cells, despite the lack of a potential signal peptide in the predicted protein sequence. Several attempts to isolate the esterase from $E$. coli after an osmotic shock, performed essentially as described by LaVallie et al. (1993), were unsuccessful. The esterase was always predominantly found in the cytoplasmic fraction of cells and less than $2 \%$ of total esterase activity was recovered in the supernatant after this treatment. Therefore, crude extracts of total cells had to be prepared. Fractionation of cell extracts containing CPO-P and the 
esterase by anion-exchange chromatography resulted in an enrichment of $7 \cdot 5$-fold for both enzymes, thus permitting comparative studies.

The enriched fraction of the esterase showed a specific brominating activity of $100 \mathrm{mU}(\mathrm{mg} \text { protein })^{-1}$ in the MCD assay, whereas the purified fraction of CPO-P showed $47 \mathrm{U}$ (mg protein) ${ }^{-1}$. This indicates that the esterase of $P$. fluorescens is able to perform the bromination of MCD, but at a lower efficiency than CPO-P. The enriched fraction of the esterase displayed a specific esterase activity of $89 \mathrm{U}$ (mg protein) ${ }^{-1}$ for the hydrolysis of $p \mathrm{NPA}$ at $\mathrm{pH} 7$. With CPO-P, no detectable esterase activity was observed in situ but significant esterase activity was detected in the colorimetric assay with $p$ NPA. The enriched fraction of CPO-P gave a specific esterase activity of $1.8 \mathrm{U}$ (mg protein $)^{-1}$ at $\mathrm{pH} 8.5$. Furthermore, significant esterase activity was also measured spectrophotometrically in crude extracts of $S$. lividans overexpressing BPO-A1, BPO-A2 or CPO-L (unpublished results). This shows that the bacterial haloperoxidases are also capable of performing the hydrolysis of $p$ NPA, but in this case at a lower efficiency than the esterase of $P$. fuorescens.

The esterase of $P$. fluorescens is the first known example of another type of enzyme related to the bacterial non-haem haloperoxidases, sharing with them common features at the structural, immunological and catalytic levels. The fact that the esterase displays brominating activity indicates that it possesses the entire catalytic machinery required to perform the oxidation of $\mathrm{Br}^{-}$during halogenation. These findings are important because the catalytic mechanisms of halogenation by the bacterial haloperoxidases is very poorly understood. Haag et al. (1991) postulated that a methionine residue could be involved in the catalytic process. However, counterevidence was obtained when more bacterial haloperoxidase genes were sequenced since no methionine was found conserved at a similar position in six different bacterial haloperoxidases. Consequently, it seems unlikely that one of these non-conserved residues plays a crucial role in the catalytic mechanism of halogenation.

Esterases belong to the large enzyme family of serinehydrolases, comprising various proteases, lipases, esterases and other hydrolases. They are characterized by the presence of a catalytic triad in their active site (Brady et al., 1990; Schrag et al., 1991) responsible for the hydrolysis of ester or amide bonds, which includes a nucleophilic amino acid, usually serine, an acidic residue (aspartic or glutamic acid) and finally a conserved histidine residue. Noteworthy is the conservation of a consensus motif $\mathrm{GlyX}_{1}-$ Ser- $\mathrm{X}_{2}$-Gly, around the nucleophilic active serine residue, due to potential steric constraints (Ollis $e t$ al., 1992). Of special interest was the identification of the motif Gly-Phe-Ser-Met-Gly in the esterase sequence, around Ser95 as indicated in Fig. 2, matching perfectly the consensus pattern. This result differs from the previously reported data in which no serine motif could be identified in the esterase sequence (Choi et al., 1990; Kim et al., 1993). The presence of the serine consensus motif in the esterase confirmed that this enzyme is a typical serine hydrolase which performs hydrolysis of ester bonds after nucleophilic attack of the hydroxyl group from the active serine residue. Studies of inhibition by PMSF, a serinehydrolase inhibitor (Gold \& Fahrney, 1964; Kraut, 1977), further support the involvement of the active serine in the catalytic mechanism of the esterase (unpublished results).

Very surprisingly however, the serine-consensus motif was present in all haloperoxidases, at the same position as in the esterase sequence, in a strongly conserved domain around position 101 in the multi-alignment (Fig. 3). The presence of the characteristic motif of serine-hydrolases in the bacterial non-haem haloperoxidases strongly emphasizes the structural and functional relationship between both enzyme families, with the esterase of $P$. fluorescens as a link between them.

Despite a quite low overall sequence homology, it was possible to align the haloperoxidases and esterase sequences with various serine-hydrolases such as the dienelactone hydrolase, DLH, from Pseudomonas sp. B13 (Frantz et al., 1987) and the dehalogenase, Hal, from Xantbobacter autotrophicus (Janssen et al., 1989), (data not shown). The three-dimensional structure of DLH and Hal has been elucidated by X-ray diffraction (Pathak \& Ollis, 1990; Franken et al., 1991; Verschueren et al., 1993). Ollis et al. (1992) have shown that they belong to the structural family of serine-hydrolases characterized by the $\alpha / \beta$ hydrolase fold. When we superimposed the elements of secondary structure of $\mathrm{Hal}$ and DLH in the sequence multi-alignment with haloperoxidases and the esterase, we observed a striking conservation of amino acids in regions forming the $\beta$-strands in $\mathrm{Hal}$ and DLH, which constituted the backbone of the $\alpha / \beta$ hydrolase fold (unpublished results). These structural homologies led us to assume that the haloperoxidases and esterase share a similar three-dimensional organization, with the conservation of the hydrolase fold structure. Elucidation of the three-dimensional structure of BPO-A2 is under way and should confirm this hypothesis.

The above structural model allowed us to identify putative candidates for the acidic and histidine residues aligned with those of $\mathrm{Hal}$ and $\mathrm{DLH}$, which could form, together with the previously described conserved serine, a catalytic triad in the haloperoxidases and esterase. The catalytic triad of the esterase of $P$. fluorescens presumably comprises the residues Ser95, Asp223 and His252 (numbering refers to Fig. 2). A catalytic triad structurally equivalent to the one found in the esterase, $\mathrm{Hal}$ and $\mathrm{DLH}$, is also present in haloperoxidase sequences (Fig. 3), in highly conserved domains. This triad is very likely to be involved in the catalytic process leading to the hydrolysis of $p$ NPA displayed by the haloperoxidases. It is important to determine whether this triad also plays a role in the catalytic process involved in halogenation. Studies of the inhibition of CPO-P, BPO-A1 and BPO-A2 by PMSF indicate that the serine in the conserved motif plays a crucial role in halogenation (unpublished results). Sitedirected mutagenesis experiments are in progress, in order to exchange the putative active residues Ser97, 
Asp229 and His258 in CPO-P, analogous to the triad of the esterase, and to confirm the involvement of a functionally active catalytic triad in halogenation (I. Pelletier, unpublished). However, based on the high sequence similarities with the esterase, on the predicted structural homologies with various serine-hydrolases containing the $\alpha / \beta$ hydrolase fold structure and on the presence of a structurally similar catalytic triad, we conclude that the bacterial non-haem haloperoxidases belong to the serine-hydrolase family.

\section{ACKNOWLEDGEMENTS}

We gratefully thank Professor Ook Joon Yoo, Korea Advanced Institute of Science and Technology, Taejon, Korea, for providing pUE1251 and for allowing us to further analyse the esterase gene. This work was supported by the Deutsche Forschungsgemeinschaft (Pelletier I.).

\section{REFERENCES}

Altschul, S. F., Gish, W., Miller, W., Myers, E. W. \& Lipman, D. J. (1990). Basic local alignment search tool. J Mol Biol 215, 403-410.

Bantleon, R., Altenbuchner, J. \& van Pée, K.-H. (1994). Chloroperoxidase from Streptomyces lividans: isolation and characterisation of the enzyme and the corresponding gene. J Bacteriol 176, 2339-2347.

Bradford, M. M. (1976). A rapid and sensitive method for the quantitation of microgram quantities of protein utilising the principle of protein-dye binding. Anal Biochem 72, 255-260.

Brady, L., Brzozowski, A., Derewenda, Z. S., Dodson, E., Dodson, G., Tolley, S., Turkenburg, J. P., Christiansen, L., Huge-Jensen, B., Norskov, L., Thim, L. \& Menge, U. (1990). A serine protease triad forms the catalytic center of a triacylglycerol lipase. Nature 343, 767-770.

Brosius, J., Dull, T. J., Sleeter, D. D. \& Noller, H. F. (1981). Gene organisation and primary structure of a ribosomal RNA operon from Escherichia coli. J Mol Biol 148, 107-127.

Choi, K. D., Jeohn, G. H., Rhee, J. S. \& Yoo, O. J. (1990). Cloning and nucleotide sequence of an esterase gene from Pseudomonas Aluorescens and expression of the gene in Escherichia coli. Agric Biol Chem 54, 2039-2045.

Chung, C. T., Niemela, S. L. \& Miller, R. H. (1989). One step preparation of competent $E$. coli: transformation and storage of bacterial cells in the same solution. Proc Natl Acad Sci US 4 86, 2172-2175.

Dawson, J. H. \& Sono, M. (1987). Cytochrome P-450 and chloroperoxidase: thiolate ligated heme enzymes. Spectroscopic determination of their active site structures and mechanistic implications of thiolate ligation. Chem Rev 87, 1255-1276.

De Boer, E. \& Wever, R. (1988). The reaction mechanism of the novel vanadium bromoperoxidase. J Biol Chem 263, 12326-12332.

Devereux, J., Haeberli, P. \& Smithies, O. (1984). A comprehensive set of sequence analysis programs for the VAX. Nucleic Acids Res 12, 387-395.

Donnelly, P. K. \& Crawford, D. L. (1988). Production by Streptomyces viridosporus $\mathrm{T} 7 \mathrm{~A}$ of an enzyme which cleaves aromatic acids from lignocellulose. Appl Environ Microbiol 54, 2237-22.44.

Franken, S. M., Rozeboom, H. J., Klak, K. H. \& Dijkstra, B. W. (1991). Crystal structure of haloalkane dehalogenase: an enzyme to detoxify halogenated alkanes. EMBO J 10, 1297-1302.

Frantz, B., Ngai, K. L., Chatterjee, D. K., Ornston, L. N. \& Chakrabarty, A. M. (1987). Nucleotide sequence and expression of clc $D$, a plasmid-borne dienelactone hydrolase gene from $P$ seudomonas sp. strain B13. J Bacteriol 169, 704-709.

Gold, A. M. \& Fahrney, D. (1964). Sulfonyl fluorides as inhibitors of esterases. Formation and reactions of phenylmethanesulfonyl $\alpha$ chymotrypsin. Biochemistry 6, 783-791.

Gribskov, M., Devereaux, J. \& Burges, J. (1984). The codon preference plot: graphic analysis of protein coding sequences and prediction of gene expression. Nucleic Acids Res 12, 539-547.

Haag, T., Lingens, F. \& van Pée, K.-H. (1991). A metal ion and cofactor-independent enzymatic redox reaction: halogenation by bacterial non-heme haloperoxidases. Agnew Chem Int Ed Engl 30, $1487-1488$.

Hewson, W. D. \& Hager, L. P. (1980). Bromoperoxidase and halogenated lipids in marine algae. J. Pbycol 16, 340-345.

Janssen, D. B., Pries, F., van der Ploeg, J., Kazemier, B., Terpstra, P. \& Witholt, B. (1989). Cloning of 1,2-dichloroethane degradation genes of Xantbobacter autotrophicus GJ10 and expression and sequencing of the $d b l A$ gene. J Bacteriol 171, 6791-6799.

Kieser, T. (1984). Factors affecting the isolation of ccc DNA from Streptomyces lividans and Escherichia coli. Plasmid 12, 19-36.

Kim, K. K., Hwang, K. Y., Choi, K. D., Kang, J. H., Yoo, O. J. \& Suh, S. W. (1993). Crystallisation and preliminary X-ray crystallographic analysis of aryl esterase from Pseudomonas fuorescens. Proteins Struct Funct Genet 15, 213-215.

Kraut, J. (1977). Serine ptoteases: structure and mechanisms of catalysis. Annu Rev Biocbem 46, 331-358.

Kugimiya, W., Otani, Y., Hashimoto, Y \& Takagi, Y. (1986). Molecular cloning and nucleotide sequence of the lipase gene from Pseudomonas fragi. Biochem Biophys Commun 141, 185-190.

Laemmli, U. K. (1970). Cleavage of structural proteins during the assembly of the head of bacteriophage T4. Nature 227, 680-685.

LaVallie E. R., DiBlasio, E. A., Kovacic, S., Grant, K. L., Schendel, P. F. \& McCoy, J. M. (1993). A thioredoxin gene fusion expression system that circumvents inclusion body formation in the $E$. coli cytoplasm. Bio/ Tecbnology 11, 187-193.

Loo, T. L., Burger, J. W. \& Adamson, R. H. (1964). Bromination of phtalein dyes by the uterus of the dogfish, Squalus acanthias. Proc Soc Exp Biol Med 114, 60-63.

Manthey, J. A. \& Hager, L. P. (1989). Characterisation of the catalytic properties of bromoperoxidase. Biochemistry 28, 3052-3057.

Ollis, D. L., Cheah, E., Cygler, M., Dijkstra, B., Frolow, F., Franken, S. M., Harel, M., Remington, S. J., Silman, I., Schrag, J., Sussman, J. L., Verschueren, K. H. G. \& Goldman, A. (1992). The $\alpha / \beta$ hydrolase fold. Protein Eng 5, 197-211.

Parker, R. C. \& Seed, B. (1980). Two dimensional agarose gel electrophoresis: 'Sea Plaque' agarose dimension. Methods Enzymol 65, 358-363.

Pathak, D. \& Ollis, D. (1990). Refined structure of dienelactone hydrolase at $1.8 \AA$. $J$ Mol Biol 214, 497-525.

Pelletier, I., Pfeifer, O., Altenbuchner, J. \& van Pée, K.-H. (1994). Cloning of a second non-heam bromoperoxidase gene from Streptomyces aureofaciens ATCC 10762: sequence analysis, expression in Streptomyces lividans and enzyme purification. Microbiology 140, 509-516.

Pfeifer, O., Pelletier, I., Altenbuchner, J. \& van Pée, K.-H. (1992). Molecular cloning and sequencing of a non-haem bromoperoxidase gene from Streptomyces aureofaciens A TCC 10762. J Gen Microbiol 138, 1123-1131.

Rosenberg, M. \& Court, D. (1979). Regulatory sequences involved in the promotion and termination of RNA transcription. Annu Rev Genet 13, 319-353. 
Rosenberg, M., Roegner, V. \& Becker, F. F. (1975). The quantitation of rat serum esterases by densitometry of acrylamide gels stained for enzyme activity. Anal Biochem 66, 206-212.

Sambrook, J., Fritsch, E. F. \& Maniatis, T. (1989). Molecular Cloning: a Laboratory Manual, 2nd edn. Cold Spring Harbor, NY: Cold Spring Harbor Laboratory.

Schrag, J. D., Li, Y., Wu, S. \& Cygler, M. (1991). Ser-His-Glu triad forms the catalytic site of the lipase from Geotrichum candidum. Nature 351, 761-764.

Verschueren, K. H. G., Seljée, F., Rozeboom, H. J., Klak, K. H. \& Dijkstra B. W. (1993). Crystallographic analysis of the catalytic mechanism of haloalkane dehalogenase. Nature 363, 693-698.

Wada, K., Wada, Y., Ishibashi, F., Gojobori, T. \& Ikemura, T. (1992). Codon usage tabulated from the GenBank genetic sequence data. Nucleic Acids Res 20, 2111-2118.
Weng, M., Pfeifer, O., Krauss, S., Lingens, F. \& van Pée, K.-H. (1991). Purification, characterization and comparison of two nonhaem bromoperoxidases from Streptomyces aureofaciens A TCC 10762. $J$ Gen Microbiol 137, 2539-2546.

Wolfframm, C., Lingens, F., Mutzel, R. \& van Pée, K.-H. (1993). Chloroperoxidase-encoding gene from Pseudomonas pyrrocinia: sequence, expression in heterologous hosts and purification of the enzyme. Gene 130, 131-135.

Yanisch-Perron, C., Vieira, J. \& Messing, J. (1985). Improved M13 phage cloning vectors and host strains: nucleotide sequences of the M13mp18 and pUC19 vectors. Gene 33, 103-119.

Received 5 August 1994; revised 29 September 1994: accepted 6 October 1994. 